\title{
Kant ante la CUESTIÓN DE LA PNEUMATOlOGÍA
}

\author{
Rogelio Rovira \\ Universidad Complutense de Madrid \\ rrovira@filos.ucm.es
}

\begin{abstract}
Kant seldom uses the name "pneumatology» to designate the science of the immortality of the soul. But in many occasions he deals in an original way with the concept meant by the name. In this paper the four senses in which Kant understands this concept are distinguished and explained, namely: (I) pneumatology as the idea of a possible science; (2) pneumatology as a natural disposition; (3) theoretical-dogmatic or doctrinal pneumatology; and (4) practical-dogmatic or authentic pneumatology. The different cognitive value granted by Kant to the doctrines about immortality assembled under the various senses of the concept of pneumatology is likewise considered.

Key words: Kant, pneumatology, immortality.
\end{abstract}

Recibido: I7 - 05 - 20I I . Aceptado: 29 - 06 - 201 I. 


\section{Resumen}

Kant emplea raras veces el nombre de «pneumatología» para denominar a la ciencia de la inmortalidad del alma. Pero en muchas ocasiones se ocupa de manera original del concepto significado por el nombre. En este trabajo se distinguen y se exponen los cuatro sentidos en que Kant entiende este concepto, a saber: (I) pneumatología como idea de una ciencia posible; (2) pneumatología como disposición natural; (3) pneumatología dogmático-teórica o doctrinal; y (4) pneumatología dogmático-práctica o auténtica. Se considera asimismo el diferente valor cognoscitivo que Kant concedió a las doctrinas sobre la inmortalidad que se cobijan bajo los diversos sentidos del concepto de pneumatología.

Palabras clave: Kant, pneumatología, inmortalidad.

«Dios, libertad e inmortalidad del alma son los problemas a cuya solución tienden, como a su último y único fin, todos los preparativos de la metafísica» ${ }^{\mathrm{I}}$. A pesar del expreso reconocimiento de Kant de que es el intento de encontrar respuesta satisfactoria a estas tres grandes cuestiones el que se halla en el centro de su labor intelectual, es preciso reconocer que la solución que el filósofo ofreció del último problema citado - el problema de la inmortalidad del alma - ha recibido parca atención por parte de los estudiosos de su pensamiento ${ }^{2}$. Este relativo descuido resulta todavía más llamativo cuando se repara no solo en el peso que efectivamente tiene el asunto de la pervivencia del alma humana en el corpus de los escritos kantianos, sino también en el hecho de que la respuesta que

${ }^{\mathrm{I}} K U$, \9I, Ak V, 473. Cf. $K r V, \mathrm{~B} 7, \mathrm{~B} 395$ Anm. Sobre las abreviaturas utilizadas para citar las obras de Immanuel KanT véase la nota al final de artículo.

${ }^{2}$ Una notable excepción la constituye la excelente tesis doctoral, todavía inédita, de Pedro Jesús Teruel: Cierre escéptico y apertura crítica de la pneumatología kantiana. Del problema alma-cuerpo al postulado de la inmortalidad en la filosofia de Immanuel Kant, Madrid: Universidad Nacional de Educación a Distancia 2006. Vid. también el libro de este mismo autor: Mente, cerebro y antropología en Kant, Madrid: Tecnos 2008.

Tópicos 4I (20II) 
Kant halló a este problema no puede por menos que arrojar luz abundante sobre temas cruciales de su filosofía, como son la cuestión de la naturaleza de la subjetividad humana y la de su último destino moral.

En ocasiones, ciertamente muy contadas, Kant recoge el estudio de la índole espiritual e inmortal del alma humana bajo la rúbrica de «pneumatología» (Pneumatologie) ${ }^{3}$. Una sola vez, en un escrito que no llegó a publicar, utiliza con este mismo fin la denominación de «pneumática» (Pneumatik $)^{4}$. Como es sabido, ambos términos tienen como raíz común la voz griega pneuma, que significa «espíritu» ${ }^{5}$.

Kant conoció acaso el vocablo «pneumatología» merced al uso que de él hicieron ciertos pensadores del siglo XVII y de la primera mitad del XVIII. Lo incorporó así al repertorio de los suyos para designar con este nuevo término una de las partes de la metafísica. $Y$ aunque es verdad que del nombre mismo hizo poco uso, no ocurre lo mismo, sin embargo, con el concepto significado por el nombre, que el filósofo entendió, de manera original, en varios sentidos, de los que se ocupó a lo largo de toda su obra. ¿En qué sentidos comprende Kant el concepto de pneumatología? ¿Qué valor cognoscitivo concedió a las diversas doctrinas que se cobijan bajo esos diversos sentidos? Responder a estas cuestiones mostrará la trascendencia que Kant otorgó al problema de la inmortalidad del alma y ofrecerá una visión de conjunto de los intentos que el filósofo dedicó a su esclarecimiento.

Para llevar a cabo las tareas propuestas, es menester reparar en que, así como de un concepto cabe dar una definición nominal, que se limita a explicarlo, sin informar de la realidad objetiva que pudiera correspon-

${ }^{3}$ Cf., por ejemplo, TG, I, 4, Ak II, 352; también KU, \89, \9I, Allg. Anm. zur Teleol., Ak V, 46I, 473, 479. El término y sus derivados, tanto en su versión latina como en su versión alemana, aparecen también en algunas Reflexiones y en los apuntes de las lecciones de metafísica de Kant.

${ }^{4}$ Cf. $F M$, Ak XX, 3 IO.

${ }^{5}$ En su obra principal el filósofo emplea en dos ocasiones un nuevo vocablo derivado de esa misma raíz, "pneumatismo» (Pneumatismus), pero ya no para designar la ciencia del espíritu, sino para referirse a la posición filosófica que sostiene que solo existen las sustancias pensantes espirituales y que, por tanto, la materia es puro fenómeno o apariencia. Cf. $K r V$, A 379, B 433. 
derle, también de la pneumatología es posible ofrecer una descripción sin ocuparse todavía de la cuestión de su validez científica. Hay que tratar así, ante todo, de lo que podríamos llamar la pneumatología «como idea de una ciencia posible», para servirnos de una expresión general acuñada por el propio Kant ${ }^{6}$. En este primer respecto, en los escritos del filósofo de Königsberg se observa una contracción del concepto de pneumatología frente al más amplio propuesto por sus predecesores.

Pero al igual que la definición real de un concepto sobrepuja su mera definición nominal, al hacer constar la posibilidad real de la cosa definida, así también es imprescindible estudiar la pneumatología según su realidad como ciencia. Sirviéndonos de una terminología de cuño kantiano que, sin embargo, el filósofo no emplea en este contexto, hay que considerar en este caso la pneumatología en tres nuevos sentidos, a saber: la pneumatología como disposición natural, la pneumatología «dogmáticoteórica», o pneumatología «doctrinal», y la pneumatología «dogmáticopráctica», o pneumatología «auténtica». Pues, en efecto, en este segundo respecto, Kant entiende el concepto de pneumatología en tantas significaciones cuantas advierte en el concepto mismo de metafísica a tenor de su posibilidad real como ciencia ${ }^{7}$.

Examinemos, pues, por separado los diversos sentidos del concepto de pneumatología tal como aparecen y se descubren en la obra de Kant, destacando expresamente, en su caso, el diverso valor cognoscitivo que el filósofo otorga a los esfuerzos intelectuales agrupados bajo cada uno de esos significados.

${ }^{6} \mathrm{Cf} . \mathrm{KrV}$, B 866.

${ }^{7}$ Sobre los distintos sentidos de metafísica en la obra de Kant puede verse Rogelio Rovira: «Von der mannigfachen Bedeutung der Metaphysik nach Kant», en Volker Gerhardt, Rolf Horstmann und Ralph Schumacher, Kant und die Berliner Aufklärung, Berlin-New York: Walter de Gruyter 200I, Bd. 2, pp. 646655 .

Tópicos 4I (20II) 


\section{La pneumatología como idea de una ciencia posible}

Según parece, las voces de «pneumatología» y «pneumática», tomadas como sinónimas, fueron introducidas por vez primera en el ámbito alemán por Johann Heinrich Alsted en su obra de I620 Cursus philosophici encyclopaedia. Con ellas el teólogo reformado y polígrafo alemán, quiso designar la parte de la metafísica que se ocupa del estudio de los espíritus, tanto del espíritu increado de Dios cuanto de los espíritus creados de los ángeles y las almas humanas ${ }^{8}$. En su Compendium philosophicum, publicado unos años después, en I626, escribe, en efecto, este prolífico autor: «La pneumática es la ciencia que trata de la naturaleza del espíritu (Pneumatica est scientia de natura spiritus)». Distingue dos especies: la pneumática general (pneumatica generalis), que versa sobre la naturaleza del espíritu absolutamente considerado, al que pertenecen las características generales de la inmaterialidad, la invisibilidad, la indivisibilidad y la vida intelectiva, y la pneumática especial (pneumatica specialis), que estudia el espíritu increado, o Dios, y los espíritus creados de los seres angélicos y de los hombres. Sobre el espíritu creado en general afirma Alsted que es propio de su naturaleza «ser simple, inmortal, y dotado de entendimiento y voluntad (In genere natura spiritus creati est, esse simplicem, immortalem, intellectu et voluntate praeditum)». Y respecto del espíritu humano el enciclopedista hace notar expresamente el peculiar aspecto bajo el que lo estudia la pneumática: «El alma del hombre se considera aquí en cuanto a su esencia absoluta, en la medida en que no se refiere al cuerpo (Anima hominis hic consideratur quantum ad essentiam absolutam, quatenus non refertur ad corpus)»?.

${ }^{8}$ Cf. Johann Heinrich Alsted: Cursus philosophici encyclopaedia, Herborn I620. Vid. Max Wundt: Die deutsche Schulmetaphysik des 17. Jahrhundert, Tübingen: J.C.B. Mohr (Paul Siebeck) I939, p. I70.

${ }^{9}$ Alsted: Compendium philosophicum, exhibens methodum, definitiones, canones, distinctiones et quaestiones per universam philosophiam, Herbonae Nassoviorum: Corvinas et Mudersprach I626, pp. 97-98. Vid también el cuadro sinóptico de las divisiones de la pneumática en la p. 1767. 
El nombre y el concepto de pneumatología o de pneumática encontraron eco en la obra de filósofos que influyeron en la formación del pensamiento de Kant. Christian Thomasius somete a dura crítica las pretensiones de los que cultivan la pneumática o ciencia de las sustancias espirituales, esto es, de Dios, los ángeles y las sustancias separadas ( $\mathrm{De}$ spiritualibus agit Pneumatica, scilicet de Deo, Angelis et anima separata»), a los que, entre otras cosas, acusa de pretender saber del alma humana separada del cuerpo cuando ni siquiera saben cosa segura de ella en su estado de unión con él: «O miseros vero homunciones, qui penetrare velint cogitationibus suis statum animae separatae, cum non penetrare possint ex acte statum animae corpori junctae» ${ }^{\mathrm{IO}}$. También Christian Wolff incluye la pneumática en el seno de la enciclopedia de las ciencias filosóficas, al enseñar que esta ciencia, que trata de los espíritus, está constituida por la psicología y la teología natural, y que, junto con la ontología y la cosmología general, forma parte, a su vez, de la metafísica: «Psychologia et Theologia naturalis nonnunquam Pneumaticae nomine communi insigniuntur, et Pneumatica per spirituum scientiam definiri solet. Ontologia vero, Cosmologia generalis et Pneumatica communi Metaphysicae nomine compellantur. Est igitur Metaphysica scientia entis, mundi in genere atque spirituum» ${ }^{\mathrm{II}}$. Por su parte, Christian August Crusius, en su Entwurf der nothwendigen Vernunftwahrheiten, obra que sin duda Kant conocía, expresa su convencimiento de que en todo mundo tiene que haber espíritus, que han de constituir, por lo demás, su parte principal y más

\footnotetext{
${ }^{\text {Io }}$ Christian Thomasius: Introductio ad philosophiam aulicam, seu lineae primae libri de prudentia cogitandi et ratiocinandi, ubi ostenditur media inter praejudicia Cartesianorum, et ineptias Peripateticorum, veritatem inveniendi via, Lipsiae: Apud Autores I688, \26 y \30, pp. I4I y I42. (Reproducción fotostática en: Christian Thomasıus: Ausgewälte Werke. Bd. I. Hrsg. von Werner Schneiders. Hildesheim-Zürich-New York: Georg Olms I993).


pertractata et ad usum scientiarum atque vitae aptata. Praemittitur discursus praeliminaris de philosophia in genere, Francofurti et Lipsiae 1740, editio tertia emendatior, \79, p. 36. (Reproducción fotostática en: Christian Wolff: Gesammelte Werke, II. Abt., Bd. I.I. Édition critique par Jean École. HildesheimZürich-New York: Georg Olms I983).
} 
noble, es más, el fin propio del mundo. «De ahí que — escribe — la parte de la cosmología metafísica que trata de lo que es necesario en la esencia de los espíritus (was in dem Wesen der Geister notwendig ist) se pueda separar convenientemente en una ciencia especial y llamarla pneumatología metafísica (metaphysische Pneumatologie) o doctrina metafísica de los espíritus (metaphysische Geisterlehre)» ${ }^{\mathrm{I}}$. Y, en fin, en la Metaphysica de Alexander Gottlieb Baumgarten, que le servía a Kant de base para sus lecciones universitarias, se afirma que la ciencia que estudia los fines que Dios ha perseguido al crear las diversas criaturas es la teleología, que es física, cuando trata de los fines de los cuerpos, y pneumática, cuando versa sobre los fines de los espíritus: «Scientia finium in creaturis divinorum est teleologia, tam physica, corporum, quam pneumatica, fines spirituum exhibens» ${ }^{\mathrm{I}}$.

Desde muy pronto, acaso desde I766, año en que publicó su libro Los sueños de un visionario, Kant sometió el concepto de pneumatología legado por sus predecesores a una doble restricción. La crítica que el filósofo llevó a cabo de las elucubraciones de Emmanuel Swedenborg sobre el mundo de los espíritus tuvo, en efecto, como primera consecuencia excluir del objeto de estudio de la pneumatología, entendida como ciencia en principio posible, tanto el espíritu divino cuanto los espíritus creados no humanos. Esta es la primera restricción mencionada. En verdad, a diferencia de Wolff, para Kant la teología racional no forma parte de la pneumática. La razón principal de ello es acaso que de la índole espiritual del ser supremo solo cabe un concepto negativo, que «resulta de negarle las propiedades de la materia que contradigan a una sustancia infinita y absolutamente necesaria» ${ }^{\mathrm{I}}$, y, sin embargo, una ciencia ha de empe-

\footnotetext{
${ }^{\mathrm{I} 2}$ Christian August Crusius: Entwurf der notwendigen Vernunft-Wahrheiten, wiefern sie den zufälligen entgegen gesetzet werden, Leipzig: verlegts Johann Friedrich Gleditsch I745, \5, p. 8. (Reproducción fotostática en: Christian August Crusius: Die philosophischen Hauptwerke. Bd. 2. Hrsg. von Giorgo Tonelli. Hildesheim: Georg Olms I964).

${ }^{13}$ Alexander Gottlieb Baumgarten: Metaphysica, Halae Magdeburgicae, Impensis carol. Herman: Hemmerde I757, editio IV, \ 946. (Reproducido en: Ak XVII, I94).

${ }^{\mathrm{I}} T \mathrm{TG}, \mathrm{I}, \mathrm{I}, \mathrm{Ak}$ II, 32I Anm.
} 
ñarse sobre todo en descubrir las propiedades positivas que caracterizan a su objeto. Pero tampoco la pneumatología puede ocuparse del estudio de todo espíritu creado, como sostenía Crusius. En la mencionada obra, Kant lo puso de relieve de manera especialmente clara al construir, en uno de sus capítulos, una presunta teoría sobre el mundo espiritual, que luego el propio filósofo calificó de «cuento del país de Jauja de la metafísica» (Märchen aus dem Schlaraffenlande der Metaphysik) ${ }^{\mathrm{I}}$. Y es que, en efecto, según escribe Kant, «se puede admitir la posibilidad de seres inmateriales sin temor de ser refutado, aunque también sin esperanza de poder demostrar esa posibilidad mediante argumentos racionales» ${ }^{\mathrm{I}}$.

La pneumatología, pues, ha de ocuparse tan solo, según Kant, del espíritu del hombre y, en verdad, como quería Alsted, en tanto que separado del cuerpo. No cabe, pues, confundir la pneumatología con la psicología: mientras que esta es la ciencia que estudia el alma (Seele, psyche) como principio vital del cuerpo, la pneumatología estudia el espíritu (Geist, pneuma), que, por esencia, está separado de todo lo material. Así lo confirma Kant en una de sus reflexiones de los años I773-I775: «Espíritu (Geist) es una inteligencia pura (puro es lo que está separado de todo lo que es heterogéneo). Por tanto, el espíritu es una inteligencia, separada de todo comercio con cuerpos. Si en la psychologia rationalis abstraigo de todo commercium con cuerpos, entonces del concepto del alma (Seele) nace el del espíritu y la psychologia se convierte en pneumatologia» ${ }^{17}$.

${ }^{\mathrm{I}}{ }^{T} \mathrm{~T}, \mathrm{II}, 2, \mathrm{Ak} \mathrm{II}, 356$.

${ }^{16} T G, \mathrm{I}, 2, \mathrm{Ak}$ II, 323.

${ }^{17}$ Refl. ${ }^{\circ}$ 4728, Ak XVII, 689. Es verdad que en los apuntes de metafísica tomados por Pölitz se identifica la llamada psicología general con la pneumatología. Sin embargo, en ese lugar, la psicología general, que estudia la naturaleza pensante en cuanto tal, se contrapone a la psicología aplicada, que estudia la naturaleza pensante en tanto que de algún modo nos es cognoscible. Se lee allí, en efecto: «En la Psychologia generalis se trata, por tanto, del sujeto pensante en general, lo cual es la pneumatología. Pero en la Psychologia specialis se trata del sujeto pensante que conocemos, y este es nuestra alma» (Metaphysik Pölitz I27, Ak XXVIII, 222). De esta manera, la tradicional distinción de los filósofos racionalistas — que Kant hace suya — entre la psicología empírica y la psicología racional es la distinción entre dos especies de psicología aplicada. La psicología 
No obstante, el filósofo introduce en este punto una segunda e importantísima restricción: la pneumatología no ha de proponer una doctrina sistemática de la esencia del espíritu humano en cuanto tal, que recoja todos los atributos que le son propios, sino que, antes bien, ha de limitarse a encontrar razones para afirmar la pervivencia del espíritu tras su separación del cuerpo. Ya en Los sueños de un visionario advirtió Kant que todas las especulaciones sobre el mundo espiritual, e incluso todas las narraciones sobre espíritus, surgen en el fondo de nuestra necesidad de alimentar «la lisonjera esperanza de que de algún modo se permanece después de la muerte» ${ }^{18}$. La pneumatología se distingue, pues, todavía con más nitidez, de la psicología en que esta estudia el alma - y su relación con el cuerpo- en esta vida, mientras que aquella considera «la naturaleza separada del alma y la duración o no duración de su personalidad después de la muerte» ${ }^{19}$.

En tanto que ciencia en principio posible, Kant concibe, pues, a la pneumatología, en razón de su intención u objeto de conocimiento, como una ciencia de lo suprasensible, concretamente como la ciencia de lo suprasensible después de nosotros, a diferencia de la doctrina de la libertad, que es la ciencia de lo suprasensible en nosotros, y de la teología, que es la ciencia de lo suprasensible sobre nosotros ${ }^{20}$. Como es obvio, el filósofo no puede por menos de entender que la pneumatología, en este

empírica, en efecto, es «el conocimiento del objeto del sentido interno en la medida en que está tomado de la experiencia»; la psicología racional, por su parte, no es sino «el conocimiento del objeto del sentido interno en la medida en que está sacado de la razón pura» (Metaphysik Pölitz I28, Ak XXVIII, 222). No cabe confundir, por tanto, en modo alguno, ninguna de estas especies de psicología con la pneumatología. Sobre la concepción kantiana de la psicología y el valor como ciencia que le reconoció puede verse, entre otros libros: Patricia KITcher: Kant's Transcendental Psychology, New York-Oxford: Oxford University Press 1990; Andrew Broок: Kant and the Mind, Cambridge: Cambridge University Press I994; Thomas Sturm: Kant und die Wissenschaften vom Menschen, Paderborn: Mentis 2009.

${ }^{18} T G$, I, 4, Ak II, 350.

${ }^{19} \mathrm{KU}, \int 89, \mathrm{Ak} \mathrm{V}, 460-46 \mathrm{I}$.

${ }^{20}$ Cf. FM, Ak XX, 295. 
sentido, comparte con las otras dos disciplinas que conforman el todo de la metafísica — la eleuterología ${ }^{2 \mathrm{I}}$ y la teología - el hecho de que su fuente de conocimiento es la razón pura, y en absoluto la experiencia, y que su modo de conocer es a priori por conceptos, y no por construcción de conceptos, como es el caso de la matemática.

Pero, así como lo peculiar de una definición real es mostrar la realidad objetiva del concepto definido, así también lo propio de la pneumatología, en tanto que ciencia, habrá de consistir en proporcionar conocimientos efectivos sobre su objeto de estudio. ¿Es la pneumatología una ciencia efectiva y no meramente posible?

\section{La pneumatología como disposición natural o pneumatologia naturalis}

Para Kant no cabe duda de que la pneumatología es una ciencia real en un sentido incoativo o potencial: la razón humana no puede dejar de plantearse el problema de la inmortalidad del alma y de responder a él del mejor modo posible. Al igual que no puede dejar de haber una metaphysica naturalis, según la expresión del filósofo, es decir, una metafísica como disposición natural ${ }^{22}$, así tampoco puede dejar de darse, aunque Kant no lo diga de modo expreso ni la denomine de esta manera, una pneumatologia naturalis, o sea, una «pneumatología como disposición natural». La pneumatología así entendida consistiría, según las palabras del propio Kant, en «la disposición que todo hombre nota en su naturaleza de no poder satisfacerse nunca con lo temporal (como insuficiente para las disposiciones de todo su destino) $»^{23}$.

Cabe afirmar que esta disposición del hombre a no satisfacerse con lo temporal por lo que toca a su destino definitivo no necesita ser demostrada: es natural en el sentido de que se halla enraizada en la misma naturaleza de su razón y aun se identifica con ella. La visión — tremenda

\footnotetext{
${ }^{2 \mathrm{I}}$ Así denomina Kant a la doctrina de la libertad una vez en su Opus postumum, 7. Convolut, Ak XXII, I05.

${ }^{22} \mathrm{Cf} . K r V, \mathrm{~B} 2 \mathrm{I}$.

${ }^{23} \mathrm{KrV}, \mathrm{B}$ XXXII.
} 
(furchtbar) y, a la par, sublime (erhaben) - de nuestra duración ininterrumpida — escribe Kant- «está entretejida de extraña manera con la razón humana universal, porque la encontramos en todos los pueblos razonadores, en todas las épocas, vestida de uno u otro modo» ${ }^{24}$. Es, por tanto, una disposición inevitable: siempre ha habido pneumatología en este sentido y siempre la habrá ${ }^{25}$. En el examen de la cuestión de la pervivencia de nuestra personalidad tras la muerte, «la balanza del entendimiento —escribía ya Kant en Los sueños de un visionario- no es totalmente imparcial y un brazo suyo, el que lleva la inscripción esperanza del futuro, posee una ventaja mecánica que hace que incluso débiles razones instaladas en su platillo levanten del otro especulaciones que de por sí tienen un peso mayon ${ }^{26}$.

Conviene advertir que el natural e inevitable deseo de conocer nuestro destino personal tras la muerte tiene su origen no en el afán de saber, sino solo en nuestra índole moral. Así lo declara Kant al hablar en conjunto sobre las tres grandes cuestiones que conforman la metafísica: «El propósito final al que en último término apunta la especulación de la razón en el uso trascendental se refiere a tres objetos: la libertad de la voluntad, la inmortalidad del alma y la existencia de Dios. Respecto de todos los tres, el interés meramente especulativo de la razón es solo mínimo. [...] Por tanto, si estas tres proposiciones cardinales no nos hacen ninguna falta para el saber, y no obstante nuestra razón nos las recomienda con insistencia, su importancia solo debe afectar propiamente a lo práctico. [...] El propósito último de una naturaleza que nos ha dotado sabiamente al construir nuestra razón no apunta propiamente nada más que a lo moralı ${ }^{27}$. En este sentido cabe afirmar que Kant hace suya a su manera la concepción platónica según la cual la idea de lo bueno (hē toũ agathoũ idéa) es causa de la ciencia y de la verdad (aitía epistēmēs kai alētheías) ${ }^{28}$.

\footnotetext{
${ }^{24} \mathrm{EaD}, \mathrm{Ak}$ VIII, 327. Cf. $K r V, \mathrm{~B} 22 ; F M, A k$ XX, 295.

${ }^{25}$ Cf. $K r V$, A 842/B 870, A 850/B 878, B XXXI.

${ }^{26} T G$, I., 4, Ak II, 349.

${ }^{27} \mathrm{KrV}, \mathrm{A} 798-801 / \mathrm{B} 826-829$.

${ }^{28}$ Platón: Republica, VI, 508 e.
} 
Pero la pneumatología, además de ser esta disposición natural del hombre a no contentarse nunca con lo finito en lo que respecta a su destino último, ¿es también un saber logrado? ¿Se convierte, mediante el ejercicio de nuestra razón, esta disposición inevitable en certeza sobre la vida eterna?

\section{La pneumatología en sentido dogmático- teórico o pneumatología doctrinal}

Desde sus inicios, la metafísica ha tratado de desentrañar el misterio de nuestro destino ultraterreno atesorando pruebas a favor de la inmortalidad del alma sacadas de las fuentes teóricas del conocimiento. Estas pruebas, en efecto, habrían de servirnos, según la imagen platónica, de balsas que nos permitieran «arriesgarnos a realizar la travesía de la vida» ${ }^{29}$. $\mathrm{Al}$ saber que sobre la inmortalidad del alma proporciona el conjunto de dichas pruebas cabría calificarlo de "pneumatología dogmático-teórica», a tenor del primero de los tres estadios de la metafísica distinguidos por $\mathrm{Kant}^{30}$, o, si se quiere, de «pneumatología doctrinal», por analogía con la disciplina filosófica que el filósofo de Königsberg llama «teodicea doctrinal» ${ }^{3 \mathrm{I}}$. No es por ello extraño que Kant, además de prestar atención a las elucubraciones sobre el mundo de los espíritus y la eternidad elaboradas, entre otros, por Emmanuel Swedenborg o Johann Caspar Lavater, haya dedicado muchas energías espirituales al estudio de los argumentos en favor de la inmortalidad del alma propuestos por los metafísicos de su época. ¿Qué juicio le merecieron a Kant estas diversas pruebas y qué valor concedió a la pneumatología a que dan lugar?

Ya en fecha tan temprana como en torno a los años I764-I769, el pensador prusiano propuso, en una anotación escrita en su ejemplar de la Metaphysica de Baumgarten, una clasificación de las pruebas teóricas de la inmortalidad del alma, que acaso quepa considerar como exhaus-

\footnotetext{
${ }^{29}$ Platón: Phaedo, 85 d 2.

${ }^{30}$ Cf. FM, Ak XX, 26I ss., 273, 3I I.

${ }^{3 \mathrm{I}} \mathrm{Cf} . \mathrm{MpVT}, \mathrm{Ak}$ VIII, 264.
} 
tiva. Tras apuntar ciertos requisitos que toda prueba de esta índole debe cumplir inexorablemente, como los de valer no para algunos hombres, sino para todos, y no para una breve existencia tras la muerte, sino para una duración eterna, Kant clasifica en dos grupos las pruebas que son en principio posibles: «O bien se derivan primo, de la naturaleza del alma a partir de principios empíricos o a partir de conceptos a priori del ser pensante en general. La primera es psicológica, la segunda es propiamente metafísica. O bien, secundo, son teleológicas, sea por analogía con los fines físicos o con los morales. Según el orden de la naturaleza» ${ }^{32}$. Tomemos, pues, esta clasificación como guía de las consideraciones siguientes.

Como es sabido, la crítica a que sometió Kant la psicología racional, ya en la época madura de su pensamiento, le mostró que en todo razonamiento sobre el alma se esconde un paralogismo inevitable. Por esta sola razón, las pruebas de la inmortalidad que se toman de la naturaleza del alma han de carecer, por principio, de toda validez. Ciertamente, el juicio que le mereció toda prueba psicológica de la inmortalidad del alma, fundada en principios empíricos, acertó a resumirla el filósofo muy exactamente en su última Crítica: «El conocimiento del alma por la experiencia (que solo en esta vida instauramos) no pudo proporcionar un concepto de su naturaleza espiritual e inmortal», pues «su concepto es trascendente para todas nuestras facultades de conocer» ${ }^{33}$. Y también en esa misma obra pudo exponer en pocas palabras las razones de su rechazo a toda prueba metafísica de la inmortalidad del alma, sea cual sea el concepto a priori en el que se base. Pues, en efecto, el uso teórico puro, independiente de la experiencia, de nuestra razón — escribe Kant— «no nos da más que un concepto negativo de nuestro ser pensante, a saber, que ninguna de sus acciones ni ninguno de los fenómenos del sentido interno puede ser explicado de un modo materialista; por lo tanto, que sobre su naturaleza separada y la duración o no duración de su personalidad después de la muerte no nos es absolutamente posible fallar juicio

\footnotetext{
${ }^{32}$ Refl. no 4IO6, Ak XVII, $4 \mathrm{I} 7$.

${ }^{33} \mathrm{KU}$, \ 9I, Ak V, 473.
} 
alguno extensivo y determinante con fundamentos especulativos por medio de nuestra facultad de conocer teórica en su totalidad» ${ }^{34}$.

Ni siquiera la novedosa prueba metafísica que expuso Moses Mendelssohn en su célebre Fedón o sobre la inmortalidad del alma escapa a este reproche, según puso de relieve expresamente Kant en las páginas de la segunda edición de la Crítica de la razón pura que dedicó a su refutación. En el primero de los diálogos que componen su obra, Mendelssohn argumentó, en efecto, que el alma, en tanto que sustancia simple, no puede perecer naturalmente «de repente» (plötzlich), pues «la naturaleza no puede producir una aniquilación (Zernichtung)» ${ }^{35}$, esto es, un paso del ser al no ser; pero tampoco puede desaparecer el alma «progresivamente» (allmählich), porque, por mucho que la supongamos disminuida en su ser, su destrucción final supondría necesariamente ese imposible paso para la naturaleza del ser al no ser: «El alma —asevera el Sócrates mendelssohniano - no puede desaparecer para siempre: pues el último paso, por mucho que lo demoremos, sería siempre todavía un salto de la existencia a la nada, que no puede fundarse ni en la esencia de una cosa individual ni en la conexión general. Por lo tanto, perdurará, existirá eternamente» ${ }^{36}$.

El juicio de Kant sobre esta prueba es conocido. El argumento de Mendelssohn acierta, según el filósofo prusiano, al excluir de la noción de un ente simple el concepto de magnitud extensiva y afirmar la consecuencia inmediata que se deriva de esa exclusión, a saber: la imposibilidad de disolución de lo simple por descomposición inmediata o por extinción progresiva. Sin embargo, a juicio de Kant, el razonamiento del filósofo judío alemán desatiende el hecho de que no solo la noción de un

\footnotetext{
${ }^{34} \mathrm{KU}, \int 89, \mathrm{Ak} \mathrm{V}, 460$.

${ }^{35}$ Moses Mendelssohn: Phaedon oder über die Unsterblichkeit der Seele, in drey Gesprächen, Berlin und Stettin: Nicolai I767, I. Gespräch, en Moses MeNDELSsoHn: Gesammelte Schriften. Jubiläumsausgabe, 3,I, p. 70. (Reproducción fotostática de la edición de Berlin: Akademie Verla, I932: Schriften zur Philosophie und Ästhetik, III,I. Bearb. von Fritz Bamberger und Leo Strauss), Stuttgart-Bad Cannstatt: Friedrich Frommann-Holzboog I972.

${ }^{36}$ Mendelssohn: Op. cit., I. Gespräch, p. 73.
} 
ente simple es compatible con el concepto de magnitud intensiva, sino que, en rigor, a nada existente se le puede negar algún grado de realidad. Ahora bien, cualquier grado puede disminuir, pasando por todos los infinitos grados menores, hasta convertirse en nada, no, ciertamente, por descomposición o extinción, pero sí por «paulatina atenuación (remissio) de sus fuerzas»y, por tanto, «por languidecimiento (Elanguescenz)». «Por consiguiente - concluye Kant - la permanencia del alma, como mero objeto del sentido interno, sigue sin estar demostrada y sigue siendo indemostrable» ${ }^{37}$.

Pero si bien las pruebas tomadas de la naturaleza del alma son, según el parecer de Kant, inválidas por principio, no ocurre lo mismo, sin embargo, con las pruebas del segundo grupo. En general, una prueba teleológica, o «según el orden de la naturaleza», es aquella que se funda en el «principio de la finalidad» (Prinzip der Zweckmäßigkeit) y se construye mediante un razonamiento por analogía. El principio de finalidad afirma, según enseña Kant, que un objeto o un estado del espíritu o una acción están ordenados teleológicamente si no pueden ser explicados más que admitiendo como fundamento suyo una causalidad según fines, es decir, una voluntad que los ha dispuesto según la representación de cierta re$\mathrm{gla}^{38}$. Por su parte, un razonamiento por analogía es aquel que se funda en «una semejanza perfecta de dos relaciones entre cosas completamente desemejantes» ${ }^{39}$.

Entre las pruebas teleológicas a favor de la inmortalidad del alma que se fundan en la analogía con los fines físicos, dos de ellas fueron objeto de especial consideración por parte de Kant. La primera se basa en el progreso hacia la perfección que se observa en los seres naturales

${ }^{37} \mathrm{KrV}$, B 4I5. La «Refutación de la prueba de la permanencia del alma propuesta por Menselssohn» se halla en las páginas B 4I3-4I5. Sobre el concepto de «magnitud intensiva» defendido por Kant y la crítica que ha recibido por parte de pensadores como Hegel, Herbart y Brentano, puede verse Ricardo MartiNELuI: «Kant, Mendelssohn e l'immortalità dell'anima», en Studi Kantiani, XV (2002), pp. 93-I26.

${ }^{38}$ Cf. $K U, \int \mathrm{IO}, \mathrm{Ak} \mathrm{V}, 220$.

${ }^{39}$ Prol, $\int 58, \mathrm{Ak}$ IV, 357. 
y la propuso Johann Gottfried Herder, antiguo discípulo del filósofo. La segunda, de inspiración platónica, parte de la adecuación a fines de los seres naturales y se encuentra en varios pensadores de la época, como Addison, Platner, Mendelssohn, Crusius, Lessing ${ }^{40}$ y Fordyce ${ }^{4 \mathrm{I}}$.

En la primera parte de sus Ideas para una filosofía de la historia de la humanidad, y especialmente en su quinto libro, Herder se propone mostrar fundamentalmente lo que enuncia el título del capítulo que cierra el libro cuarto, a saber: que «el hombre está formado para la esperanza en la inmortalidad $»^{42}$. Para ello se apoya en el principio teleológico según el cual en la organización de los seres naturales, y especialmente en la del hombre, actúan fuerzas invisibles espirituales que la ordenan a fines. Y, reducido el argumento a su puro esquema, razona de esta manera: así como la organización material de los seres naturales muestra una progresión que tiene su miembro supremo y último en la perfección propia del ser humano, ente corpóreo y espiritual a la vez, así también la organización del ser humano ha de considerarse como el primer e inferior miembro de una serie de seres de carácter puramente espiritual, de los que el hombre formará parte tras la muerte. Escribe Herder: «Todo está enlazado en la naturaleza; un estado tiende a otro y lo prepara. Por lo tanto, si el hombre cerró la cadena de la organización terrenal siendo su miembro último y más elevado, precisamente por eso él empieza también la cadena de una especie de criaturas superior, de la cual él es el miembro más bajo; de ahí que probablemente sea el anillo intermedio entre dos sistemas de la creación enlazados» ${ }^{43}$.

40 Tales son los autores que cita Lewis White BECK en su A Commentary on Kant's Critique of Practical Reason, Chicago-London: The University of Chicago Press I960, p. 266 n. I8.

${ }^{4 \mathrm{I}}$ Según propone Rolf George en su artículo «Immortality», en Hoke RoBINSON (ed.): Proceedings of the Eighth International Kant Congress (Memphis I985), Milwaukee: Marquette University Press, pp. 669-677. Vid. también TeRUEL: Cierre escéptico..., pp. 257-258.

${ }^{42}$ Johann Gottfried Herder: Ideen zur Philosophie der Geschichte der Menschheit. Hrsg. von Heinz Stolpe, Berlin und Weimar: Aufbau I965, Bd. I, 4. Buch, 7. Kap., p. I62.

${ }^{43}$ Herder: Op. cit., Bd. I, 5. Buch, 6. Kap., p. I9I. 
En la recensión que Kant escribió de la obra de Herder dejó consignadas dos objeciones principales contra esta presunta prueba. La primera se dirige al principio teleológico subyacente a la argumentación: explicar el progreso hacia la perfección en la organización de los seres naturales mediante la «ficción poética» de unas fuerzas espirituales vivificadoras equivale a tratar de aclarar lo oscuro por lo más oscuro. «Pero, ¿qué se debe pensar en general — pregunta retóricamente Kant — de la hipótesis de fuerzas invisibles que producen la organización y, por tanto, del proyecto de querer explicar lo que no se comprende a partir de lo que todavía se comprende menos?» ${ }^{44}$. La segunda objeción concierne al razonamiento mismo: no hay analogía entre el progreso en la organización material de los seres naturales que culmina en el hombre y la elevación del hombre a formar parte tras la muerte de una nueva organización espiritual de seres, porque la progresión de la naturaleza se hace, por así decir, a favor de la especie y en contra del individuo, mientras que en la cuestión de la inmortalidad del alma lo que es menester asegurar es la supervivencia de cada individuo. «No hay, pues, la más mínima semejanza — declara tajantemente Kant- entre la elevación natural del mismo hombre a una organización más perfecta en otra vida y la escala graduada que cabe pensar entre especies e individuos completamente diferentes de un reino natural. Aquí la Naturaleza no nos deja ver sino que abandona a los individuos a la completa destrucción y que solo conserva la especie; pero allí se pretende saber si también el individuo de la especie humana sobrevivirá a su destrucción aquí en la tierra» ${ }^{45}$.

La segunda prueba teleológica referida, la que parte de la adecuación a fines de los seres naturales, la expuso Kant, en sus rasgos esenciales, en un conocido lugar de la segunda edición de su obra principal ${ }^{46}$. El razonamiento toma como punto de partida el principio según el cual en los seres vivos de la naturaleza «no hay ningún órgano, ninguna facultad, ningún impulso, nada, en suma, prescindible o desproporcionado a su uso y, por tanto, desprovisto de fin, sino que todo es exactamente

\footnotetext{
${ }^{44}$ RezHerder, Ak VIII, 53-54.

${ }^{45}$ RezHerder, Ak VIII, 53.

${ }^{46} \mathrm{Cf}$. para las citas que siguen $\mathrm{KrV}, \mathrm{B} 425-426$.
} 
conforme a su destino en la vida». Solo la vida humana — prosigue el argumento- parece constituir la única excepción a este principio teleológico de la naturaleza, pues las disposiciones naturales del hombre, «no solo los talentos e impulsos para hacer uso de ellas, sino principalmente la ley moral en él, sobrepasan tanto todo provecho y utilidad posibles en esta vida, que esa ley le enseña a estimar sobre todas las cosas la mera conciencia de tener el ánimo rectamente templado, aunque falte toda ventaja y por encima incluso de la sombra fugaz de la vana gloria». En razón de la analogía con la omnipresente finalidad de los seres vivos de la naturaleza, cabe entonces esperar — concluye la prueba- que también la vida humana regida por la ley moral encontrará su cumplimiento, no en esta vida, cuya finalidad sobrepasa, sino en otra tras la muerte: así como no hay órgano sin función, así tampoco puede ser inútil la ley moral. «Siéntese el hombre interiormente llamado — escribe Kant - a hacerse digno, por su conducta en este mundo y renunciando a muchos provechos, de ser ciudadano de otro mundo mejor, que él tiene en la idea».

Kant tuvo a esta prueba en alta estima. La calificó, en verdad, de «argumento poderoso, nunca refutable» ${ }^{47}$. No obstante, no cabe desatender el hecho de que, según la doctrina del filósofo, la demostración se halla sometida a dos graves limitaciones. La primera concierne al principio teleológico en que se apoya: la Crítica del Juicio enseña, en efecto, que el principio que enuncia la finalidad de la naturaleza es un principio regulativo de la facultad del juicio reflexionante, y en modo alguno un principio constitutivo de la facultad del juicio determinante. La segunda atañe al razonamiento analógico mismo: la relación analógica solo permite pensar el término desconocido, pero nunca conocerlo en sí mismo ${ }^{48}$. En consecuencia, la prueba no proporciona saber alguno sobre la inmortalidad del alma: no nos permite «evidenciar (einsehen) — escribe Kant— la necesaria perduración de nuestra existencia mediante un simple conocimiento teórico» ${ }^{49}$. O dicho positivamente: el argumento solo nos proporciona fe doctrinal, vale decir, un asentimiento firme ante una hipótesis, la de la in-

\footnotetext{
${ }^{47} \mathrm{KrV}, \mathrm{B} 426$.

${ }^{48}$ Cf. Prol, \57, Ak IV, 357; KU, \88, Ak V, 456.

${ }^{49} \mathrm{KrV}, \mathrm{B} 426$.
} 
mortalidad del alma, que estamos autorizados a suponer, pero que nunca podemos demostrar. Así lo declara el propio filósofo: «En consideración a la excelente disposición de la naturaleza humana y a la brevedad de la vida, tan mal acomodada a esa naturaleza, puede hallarse igualmente un fundamento suficiente para una fe doctrinal en la vida futura del alma humana» ${ }^{5}$.

De las observaciones que sobre el mundo moral consigna Kant en su primera Crítica, concretamente en la sección dedicada al canon de la razón pura, se desprende una cierta prueba teleológica a favor de la inmortalidad del alma que se funda en la analogía, no con los fines físicos, sino con los morales. Se trata, sin embargo, de una prueba teórica, porque no tiene su punto de partida en un principio práctico, sino, más bien, en un juicio teórico sobre la naturaleza de la ley moral. Cabe formularla libremente del modo siguiente. Es necesario pensar que las leyes morales están gobernadas por un principio teleológico, pues si mandaran algo inadecuado al fin natural y necesario de todo ser racional, habrían de ser consideradas meras fantasías vacías. No cabe, en efecto, tener la obligación de llevar a cabo algo que de suyo es irrealizable. Ahora bien, las leyes morales, que son efectivos fundamentos subjetivos del obrar, no permiten obtener en el curso de la vida terrena el fin supremo que ordenan, a saber: lograr una felicidad adecuada a la moralidad. En efecto, en el mundo sensible no hay conexión causal alguna entre la moralidad y la felicidad. En razón, pues, del principio de la finalidad que rige a las leyes morales, es menester admitir una causa de la conexión entre la moralidad y la felicidad y un mundo en el que tal conexión se verifique: así como no puede haber mandato sin la posibilidad de su cumplimiento efectivo, así tampoco puede haber leyes morales sin los supuestos que exige su observancia. Conluye Kant: «Por tanto, Dios y una vida futura son dos de las presuposiciones que, según principios de la razón pura, son inseparables de la obligación que la misma razón pura nos impone» ${ }^{5 \mathrm{I}}$.

He aquí un pasaje que podría valer como la formulación que hace el propio filósofo de Königsberg de este argumento: «Es necesario que

\footnotetext{
${ }^{50} \mathrm{KrV}, \mathrm{A} 627 / \mathrm{B} 855$.

${ }^{51} \mathrm{KrV}$, A 81 I/B 839 .
} 
todo el curso de nuestra vida se someta a máximas morales; pero al mismo tiempo es imposible que esto ocurra si la razón no junta con la ley moral, que es una mera idea, una causa eficiente que determine para la conducta conforme a la ley moral un resultado que corresponda exactamente con nuestro fin supremo, sea en esta vida o en otra. Por consiguiente, sin un Dios y sin un mundo que ahora no es visible para nosotros, pero que esperamos, las ideas soberanas de la moralidad serán ciertamente objetos del aplauso y la admiración, pero no motores del propósito y del ejercicio, porque no colman todo el fin que es natural a todo ser racional y determinado y necesario por esa misma razón pura a priori» $5^{2}$.

Bien se observa que esta prueba no es sino una mera variante de la anteriormente considerada: en vez de apoyarse, como aquella, en el principio teleológico que gobierna la organización de los seres vivos de la naturaleza, se basa ésta en el principio de finalidad que rige el obrar moral del hombre. Y al igual que aquella no podía admitir que la organización del ser humano fuera una excepción a semejante principio, tampoco ésta puede aceptar que el fin último imperado por las leyes morales escape a toda ordenación teleológica. Por esta razón, la nueva prueba comparte con la otra sus mismas limitaciones: no permite obtener un saber sobre la inmortalidad del alma, sino que solo autoriza a formular la hipótesis,

${ }^{52} \mathrm{KrV}$, A 8I2-8I3/B 840-84I. La prueba se funda, en efecto, a mi parecer, en el hecho incontestable de que no cabe una obligación moral respecto de algo imposible de realizar. No se apoya, por tanto, en la tesis, según pretenden algunos intérpretes (cf. BECK: A Commentary..., pp. 266-267 y Victoria WIKE, «Another Look at Kant's Arguments for Immortality», en Robinson (ed.): Proceedings..., p. 662), de que sin la suposición de la inmortalidad (y de la existencia de Dios) la ley moral no podría ser un fundamento suficiente de determinación de la voluntad. Antes bien, el razonamiento parece afirmar que, puesto que la ley moral es un fundamento suficiente de determinación del querer, es menester suponer que están dadas las condiciones que hacen posible la realización del fin último que ordena: la ley moral no es, pues, la mera idea de algo irrealizable, sino un efectivo mandato. Por esta razón no cabe tampoco oponer a esta prueba, como hacen los autores citados, el reproche de que supone la heteronomía de la voluntad, tesis que ciertamente Kant rechaza de plano en sus escritos éticos. 
nunca demostrable, de la pervivencia del hombre tras la muerte. A lo sumo, pues, la vida futura sigue siendo objeto de fe doctrinal.

$\mathrm{Al}$ término de este examen de las pruebas teóricas a favor de la inmortalidad del alma, la conclusión se impone: según Kant, las pruebas puramente especulativas son por principio inválidas, por encerrar una ilusión trascendental inevitable; las que se apoyan en la experiencia para remontarse, por el camino de la analogía, a lo suprasensible, son necesariamente insuficientes, pues solo logran establecer una hipótesis indemostrable. A esta luz no puede extrañar el valor que Kant otorga a la pneumatología que hemos llamado «dogmático-teórica» o «doctrinal»: semejante pneumatología no puede constituir en modo alguno una ciencia. Es, antes bien, la doctrina de la necesaria ignorancia sobre la pervivencia de nuestra alma tras la muerte, ignorancia que no queda en modo alguno superada por la pensabilidad de la hipótesis que afirma la efectiva inmortalidad. Así como la teología no puede convertirse nunca en teosofía (es decir, en conocimiento teórico de la existencia y la esencia de Dios, que explicara la constitución del mundo y la determinación de las leyes morales), así tampoco la psicología racional puede llegar a ser nunca pneumatología (es decir, conocimiento teórico de la naturaleza espiritual del alma humana y su destino moral eterno), asevera gráfica y explícitamente $\mathrm{Kant}^{53}$.

¿Es menester contentarse con este pobre resultado que ofrecen las pruebas teóricas de la inmortalidad del alma y la pneumatología a que dan lugar?

\section{La pneumatología en sentido dogmático- práctico o pneumatología auténtica}

Kant no creyó en modo alguno que la razón haya de darse por vencida en la búsqueda de certezas sobre la perduración del alma tras la muerte. Su genio filosófico le llevó a iniciar un nuevo camino, nunca antes intentado: buscar la certeza sobre la espiritualidad e inmortalidad del

${ }^{53}$ Cf. KU, \ 89 y Allg. Anm. zur Teleol., Ak V, 460-46I y 479. 
alma, no en las fuentes teóricas, sino en las fuentes prácticas del conocimiento. Así lo afirmó el filósofo expresamente, ya en la segunda edición de su Crítica de la razón pura, una vez comprobado el fracaso de la pneumatología doctrinal: «No se ha perdido, sin embargo, lo más mínimo para el derecho y aun la necesidad de admitir una vida futura según principios del uso práctico de la razón enlazado en esto con el especulativo; porque de todos modos la mera prueba especulativa no ha podido tener nunca influjo alguno en la razón humana» ${ }^{54}$.

Como es sabido, Kant creyó convertir en realidad el derecho y la necesidad de admitir una vida futura gracias a la prueba que, bajo el epígrafe de «La inmortalidad del alma como postulado de la razón pura práctica», expuso en el capítulo segundo del segundo libro de la primera parte de su Crítica de la razón práctica. A la pneumatología a que esa prueba da lugar puede llamársela, pues, «pneumatología dogmático-práctica», por referencia al tercer y último estadio que, según Kant, ha recorrido la metafísica, o, si se prefiere, «pneumatología auténtica», por analogía con la única teodicea posible, calificada con ese adjetivo por el filósofo.

La afirmación capital de la pneumatología entendida en este sentido es aquella que atribuye al alma humana la inmortalidad «en tanto que estado en el que al hombre debe deparársele su bien o su mal en relación con su valor moral» ${ }^{55}$. Acaso lo más característico de esta nueva ciencia estriba en que la validez de esa afirmación capital suya se halla indisolublemente ligada a la ley moral y no supone por ello en absoluto una ampliación de nuestro saber. Ciertamente, la prueba que Kant aduce para justificar la referida tesis es práctica, y no teórica, porque tiene su punto de partida en ley moral. Desde el punto de vista lógico, la prueba no se construye mediante un razonamiento por analogía, sino que reviste el carácter de lo que el filósofo llama «exposición trascendental de un concepto», que consiste, como se sabe, en representar de un modo claro, aunque acaso no detallado, lo que pertenece a un concepto en tanto que principio a partir del cual cabe entender la posibilidad de otros conoci-

\footnotetext{
${ }^{54} \mathrm{KrV}, \mathrm{B} 424$.

${ }^{55}$ VNAEF, I. Abs. B, Ak VIII, 4I8.
} 
mientos sintéticos a priori ${ }^{56}$. En este caso, en efecto, el concepto de inmortalidad, entendido como ese estado en el que al hombre se le depara lo que merece respecto de su valor moral, se presenta como la condición de posibilidad del juicio práctico a priori que manda fomentar el bien supremo. Pero, desde el punto de vista de su verdad material, hay que añadir que esta peculiar argumentación ve mermada en cierta medida su validez al tomar como punto de partida para su progreso precisamente un principio sintético a priori de carácter práctico, cuyas condiciones de posibilidad han de ser pensadas también, por tanto, de un modo práctico.

Expongamos los cinco pasos en que cabe desglosar la prueba, ilustrándolos con las explicaciones literales de $\mathrm{Kant}^{57}$.

Primer paso. Punto de partida: el mandato de realizar el bien supremo.- El punto de partida de la argumentación es que la ley moral — dada como el único «factum de la razón pura práctica»— ordena la realización del fin último de la voluntad, que no es otro que el bien supremo, o sea, la consecución de la dignidad moral de ser feliz: «La realización del bien supremo en el mundo es el objeto necesario de una voluntad determinable por la ley moral».

Segundo paso. Búsqueda de la primera y más elevada condición de la posibilidad de la realización del bien supremo: la santidad de la voluntad.- La condición primera y más elevada de la realización del bien supremo no es otra que la adecuación plena de la voluntad a la ley moral, adecuación que Kant — tomando acaso el término del cristianismollama santidad. Si la ley moral ordena, como en efecto lo hace, la consecución de la dignidad moral de ser feliz, entonces manda eo ipso la santidad de la voluntad, pues no cabe aquella sin esta, según nos revela el mero análisis de los conceptos. «Pero en esta voluntad — escribe Kantla plena adecuación de las disposiciones del ánimo con la ley moral es la condición más elevada del bien supremo. Por tanto, tiene que ser tan posible como su objeto, porque está contenida en el mismo mandato de fomentar este objeto».

\footnotetext{
${ }^{56}$ Cfr. $K r V$, B 38 y B 40.

${ }^{57}$ Cf. para las citas que siguen $K p V$, Ak V, I22.
} 
Tercer paso. Búsqueda de la condición de la posibilidad de la realización de la santidad de la voluntad: el progreso práctico infinito hacia ella.- Escribe Kant: «Pero la adecuación completa de la voluntad a la ley moral es santidad, una perfección de la cual ningún ser racional en el mundo sensible es capaz en ningún momento de su existencia. Mas como esa plena adecuación está, sin embargo, exigida en tanto que prácticamente necesaria, no puede ser hallada más que en un progreso que va al infinito hacia ella, y según principios de la razón pura práctica, es necesario admitir un progreso práctico de esa índole como el objeto real de nuestra voluntad».

Cuarto paso. Búsqueda de la condición de la posibilidad del progreso práctico infinito hacia la santidad: la inmortalidad del alma.- Afirma, en efecto, Kant: «Mas este progreso infinito es posible únicamente en el supuesto de una existencia y personalidad, que prosigue hasta lo infinito, del mismo ser racional (que se llama la inmortalidad del alma)».

Quinto paso. Conclusión: la inmortalidad del alma como condición última de la posibilidad de la realización del bien supremo.- Concluye Kant su argumentación: «Así, pues, el bien supremo no es posible prácticamente nada más que bajo el supuesto de la inmortalidad del alma; por tanto, esta, como inseparablemente unida con la ley moral, es un postulado de la razón pura práctica».

Si se admite la doctrina kantiana del bien supremo, cuya enseñanza principal conforma el punto de partida de la argumentación, es claro que el paso crucial de esta prueba lo constituye el paso tercero. El segundo, en efecto, se deduce analíticamente del primero y los pasos cuarto y quinto parecen seguirse necesariamente del tercero. Lamentablemente, Kant ha formulado este tercero y decisivo paso de manera imprecisa y, por tanto, equívoca. Si se lo interpreta literalmente, la prueba incurre en una evidente aporía. Pues si la santidad de la voluntad es, en verdad, como afirma Kant, «una perfección de la cual ningún ser racional en el mundo sensible es capaz en ningún momento de su existencia», entonces tampoco podrá lograrse - frente a lo que explícitamente afirma el filósofo- «en un progreso que va al infinito hacia ella». Si la santidad no se alcanza en ningún momento, tampoco podrá alcanzarse en una infinita serie de momentos. 
Pero poder lograr la santidad es condición de posibilidad de la inmortalidad del alma y, por ende, condición de posibilidad de la realización del bien supremo. El argumento de Kant, tomado en los términos mismos en los que se expresa, es, pues, deficiente ${ }^{58}$.

Cabe, sin embargo, entender este tercer paso de la prueba en otro sentido y aun comprender que la imprecisión con que Kant lo formula es, hasta cierto punto, inevitable. La pregunta por la condición de posibilidad de la realización de la santidad de la voluntad, núcleo de ese tercer paso, puede interpretarse de este modo: ¿Cómo tiene que ser la duración de la existencia de un ser cuya voluntad está sometida a la exigencia de la santidad? La respuesta de Kant se encerraría en dos tesis, una negativa y otra positiva.

La tesis negativa rezaría así: la duración de semejante existencia no puede ser temporalmente finita, como ocurre en el caso de un ser mortal, porque ello supondría el imposible de que la santidad, esto es, la plena adecuación de la voluntad a la ley moral, fuera plena y no plena conformidad de lo que se quiere con lo que se debe querer: plena, por ser santidad;

${ }^{58}$ Esta es la objeción principal que, con toda razón, opone Antonio Mirlá́NPuelles a la argumentación kantiana en su libro inacabado La inmortalidad del alma humana. Edición póstuma dirigida por José María Barrio Maestre, Madrid: Rialp 2008, p. 202. El pasaje merece citarse por entero: «Un defecto de mucha mayor envergadura - y, tal como vamos a comprobar, imposible de corregires el que atañe a la afirmación de la necesidad de un progreso infinito encaminado hacia la plena adecuación de la voluntad a la ley moral. Según Kant, esa completa adecuación es una perfección de la que ningún ser racional es capaz en ningún momento de su existencia en el mundo sensible, por lo cual y siendo, también según él, prácticamente necesario, sólo puede encontrarse en un progreso infinito hacia esa misma completa adecuación. La ineludible objeción a esta tesis estriba en la absoluta imposibilidad de que en un proceso infinito, i.e. que nunca termina, se llegue a alcanzar algo como meta de él. En ningún momento de ese progreso puede darse la plena adecuación de la voluntad a la ley moral: si en alguno se diera esa adecuación, el progreso se habría acabado; y si nunca se acaba ese progreso, nunca la adecuación de la voluntad a la ley moral será completa o plena, contrariamente a lo que sostiene el propio Kant, para quien tal adecuación es algo contenido en el mismo mandato de procurar el bien supremo». 
no plena, por tener un límite temporal. En efecto, por una parte, la santidad no es una perfección que quepa alcanzar en un momento dado del tiempo de una vez por todas: no es santidad si, por así decirlo, decae y no perdura indefinidamente gracias a la voluntad que la ha hecho una vez posible. Por otra parte, la santidad tampoco puede obtenerse mediante la suma de todos los momentos de una vida que se acaba: la muerte, en verdad, hace que la santidad decaiga y no persista al extinguirse el ser a cuya voluntad debe su existencia en todos los momentos de esa vida. Así cabe entender, pues, la equívoca frase de Kant según la cual de la santidad «no es capaz ningún ser racional en el mundo sensible en ningún momento de su existencia», ni en el conjunto de todos ellos, puede añadirse. Y adviértase que esta incapacidad no nace de que la voluntad humana, afectada por inclinaciones, no pueda plegarse alguna vez a las exigencias puras del deber, sino que, antes bien, la incapacidad tiene su origen en que la santidad compromete a la voluntad con una tarea infinita y la muerte es cesación de la posibilidad del cumplimiento de esa tarea ${ }^{59}$.

En consecuencia, la tesis positiva de la respuesta de Kant tendría que enunciarse de este modo: la duración de la existencia de un ser cuya voluntad está sometida a la exigencia de la santidad ha de ser temporalmente infinita, o mejor, ha de estar fuera del tiempo, en la eternidad, por así decir. A la duración de la existencia de un ser moral cabe aplicarle punto por punto lo que escribe Kant en un breve escrito sobre El final de todas las cosas, a saber, que es «una magnitud absolutamente inconmensurable con el tiempo (duratio noumenon), de la que, naturalmente, no podemos hacernos ningún concepto (a no ser meramente negativo)» ${ }^{60}$. Así habría que entender, por tanto, el concepto de «progreso práctico infinito» utilizado en la prueba por Kant y aun disculpar su carácter equívoco, que es en cierta medida inevitable. Pues en este caso resulta imprescindible una doble perspectiva: desde el punto de vista de nuestra existencia sen-

${ }^{59}$ Este punto esencial ha sido bien visto por Pedro Jesús Teruel en sus dos libros citados. Así, por ejemplo, en Mente, cerebro..., p. I84, se lee: «...el ejercicio de la libertad ajustada a leyes morales no es una magnitud susceptible de ser colmada o recorrida: consiente siempre realizaciones más altas, más adecuadas».

${ }^{60} \mathrm{EaD}, \mathrm{Ak}$ VIII, 327. 
sible, que transcurre en el tiempo, la santidad, que va más allá de toda medida y, por tanto, de todo límite temporal, solo podría obtenerse en un progreso temporal infinito; sin embargo, desde el punto de vista de nuestra existencia inteligible, la ley moral «no reconoce ninguna diferencia de tiempo» ${ }^{6 \mathrm{I}}$ : la voluntad que está sometida al mandato de la santidad vive en consecuencia, por así decir, una vida intemporal, eterna, «inacabable», de «infinito progreso», si se admite la imprecisión, apenas evitable, de estas expresiones.

La interpretación apuntada parece confirmarla la observación que Kant aduce tras proponer su prueba de la inmortalidad del alma. En ella opone, en efecto, la perspectiva de los seres racionales finitos a la del ser racional infinito: «Para un ser racional, pero finito, solo es posible el progreso al infinito desde los grados inferiores a los superiores de la perfección moral. El Infinito, para el que la condición del tiempo no es nada, ve en esta serie, para nosotros infinita, el todo de la adecuación con la ley moral, y la santidad, que su mandato exige incesantemente para ser conforme a su justicia en la participación que él determina a cada uno en el bien supremo, se ha de hallar en una única intuición intelectual de la existencia de los seres racionales» ${ }^{62}$.

En definitiva, la ley moral, al exigirnos la obtención del bien supremo, nos propone una tarea, la santidad, que de suyo es atemporal, no circunscrita al tiempo ni a ninguno de sus momentos. Para nosotros, que no podemos desprendernos de la condición temporal, el cumplimiento de la tarea se nos presenta como infinito. En sí misma, en cambio, la

\footnotetext{
${ }^{6 \mathrm{I}} \mathrm{KpV}, \mathrm{Ak} \mathrm{V,99.}$

${ }^{62} \mathrm{KpV}, \mathrm{Ak} \mathrm{V}, \mathrm{I} 23$. Estas palabras de Kant parecen desautorizar, por lo demás, la interpretación de Cris W. SuRprenant, expuesta en su artículo «Kant's Postulate of the Immortality of the Soul», en International Philosophical Quarterly, 48 (2008), pp. 85-98, según la cual «contrariamente a la concepción del alma defendida por Platón y por algunos cristianos, tras la muerte el alma no ingresa, para Kant, en una vida futura dichosa en la que ya no se está tentado de hacer el mal, esto es, en una vida futura donde el alma llega a ser santa» (p. 92). Si fuera efectivamente así, a Dios — frente a lo expresamente afirmado por Kant- no le podría estar nunca dado «el todo de la adecuación con la ley moral» en una intuición única y jamás podría ejercer, por tanto, su justicia.
} 
tarea, que nos es impuesta por nuestra razón como un factum ineludible, nos revela que no podemos morir: nos traslada ineludiblemente a un mundo inteligible, fuera del tiempo, inagotable en su duración, por así decir. La ley moral en mí —escribe Kant en el conocido pasaje con el que concluye su Crítica de la razón práctica- «empieza en mi invisible yo, en mi personalidad, y me expone en un mundo que tiene verdadera infinidad $»^{63}$.

Aun si fuera aceptable esta versión del argumento en favor de la inmortalidad del alma como condición última de la posibilidad de la realización del bien supremo, no hay que olvidar, sin embargo, que Kant sostiene que la conclusión de su prueba es un postulado de la razón pura práctica. Con ello quiere decir, según la definición de "postulado» que ofrece, que semejante conclusión es, por una parte, una proposición teórica, aunque indemostrable como tal; por otra, sin embargo, que la proposición es válida incondicionalmente a priori, porque está unida necesariamente con el objeto último que nos manda la ley moral ${ }^{64}$.

Esta concepción de la prueba en tanto que postulado de la razón pura práctica supone afirmar que la aceptación de la inmortalidad del alma produce una certeza absoluta, aunque fundada únicamente en una necesidad subjetiva. Adviértase, en efecto, que la certeza a que nos conduce la conclusión de la prueba estudiada no es la certeza propia del saber, porque no cabe demostración teórica alguna de ella. Pero tampoco es, ciertamente, la certeza que corresponde a la opinión, ni siquiera a la llamada «fe doctrinal», que nos autorizaría a proponer la inmortalidad como hipótesis, ciertamente indemostrable, pero también siempre problemática y, por ello, incierta. La certeza en que nos hace reposar la prueba «moral» de la inmortalidad del alma es, antes bien, una certeza que pertenece en exclusiva a lo que Kant llama «fe racional moral», es decir, a ese particular asentimiento que, aunque insuficiente desde el punto de vista objetivo (pues la inmortalidad es incognoscible teórica-

\footnotetext{
${ }^{63} \mathrm{KpV}, \mathrm{Ak} \mathrm{V}, \mathrm{I} 62$.

${ }^{64} \mathrm{Cf} . K p V$, Ak V, I22. Sobre el concepto kantiano de postulado puede verse Rogelio Rovira: «La noción de postulado en la filosofía de Kant», en Revista Venezolana de Filosofia, 2I (I986), pp. 77-88.
}

Tópicos 4I (2OII) 
mente), resulta suficiente subjetivamente (ya que es condición necesaria de la realización de un deber $)^{65}$.

Con todas estas consideraciones Kant declara, a la vez, la necesaria limitación de la validez de la prueba que propone en favor de la perduración del alma. No puede ser, en efecto, una prueba kat'alētheian, sino tan solo una prueba kat'ántrōpon: la prueba no establece ni demuestra en modo alguno en qué consiste la inmortalidad y cómo es en sí misma, sino que la establece y la determina para el hombre en general según principios racionales que son necesarios para el juicio moral ${ }^{66}$. Dicho de otro modo: según Kant, tenemos, en verdad, el derecho de afirmar con certeza la inmortalidad del alma, pues la persecución del deber de fomentar el bien supremo, que es un objeto necesario del querer, aunque suprasensible, nos autoriza a admitir semejante inmortalidad como condición necesaria de su realización, por más que esa condición sea también suprasensible. Sin embargo, esta afirmación no supone en modo alguno una ampliación del conocimiento teórico de la razón y solo tiene justificación «en propósito práctico» ${ }^{67}$, con vistas al cumplimiento efectivo del deber.

Con la admisión de la inmortalidad del alma a partir del dato de la ley moral, la razón llega, pues, al máximo de lo que por sí misma puede alcanzar respecto de la pneumatología. De este modo, lo que Kant tuvo que sostener respecto de la metafísica toda, también lo afirma de hecho para la pneumatología. Pues así como el filósofo tuvo que suprimir el saber de lo que está más allá de la experiencia para dejar sitio a la fe racional que nos da noticia de lo suprasensible ${ }^{68}$, así también tiene que eliminar la pneumatología que pretende lograr conocimiento para hacer lugar a la pneumatología que nace de la fe moral. En ello estriba, en efecto, la validez y, a la par, la limitación de la pneumatología que hemos llamado «dogmático-práctica» o «auténtica».

\footnotetext{
${ }^{65} \mathrm{Cf} . \mathrm{KU}, \int 9 \mathrm{I}, \mathrm{Ak} \mathrm{V}, 469$.

${ }^{66} \mathrm{~A}$ la prueba «moral» de la inmortalidad del alma cabe aplicarle, en efecto, las mismas características que Kant atribuye a la llamada prueba moral de la existencia de Dios. Cf. KU, \90, Ak V, 462-463; FM XX, 306.

${ }^{67}$ Cf. $K p V$, Ak I22-I24; FM, Ak XX 294. VNAEF, Ak VIII, 4I 8 Anm.

${ }^{68} \mathrm{Cf} . \mathrm{KrV}, \mathrm{B}$ XXX.
} 


\section{$* * *$}

Con ocasión del estudio de los diversos significados en que Kant entiende el concepto de pneumatología, hemos tenido que recorrer la trayectoria entera que describe la filosofía crítica: lo que para el uso especulativo de la razón resulta de todo punto inalcanzable, y objeto de inevitable engaño y confusión cada vez que trata de aproximarse a él, resulta necesariamente exigido, sin embargo, para el uso práctico puro de esa misma razón. La vida moral nos lleva, en efecto, a admitir la inmortalidad del alma, cosa que de ningún modo pudo obtener nuestro afán de saber sobre la perduración en el más allá de esta vida, pero esa admisión no remedia en absoluto nuestra privación de conocimiento: solo aviva en nosotros la oscura llama, si se permite el oxímoron, de la fe moral. Las consideraciones expuestas han puesto de relieve, en verdad, la irrenunciable convicción de Kant según la cual el hombre, por razones estrictamente morales, no puede contentarse con lo temporal y lo finito respecto de su destino último y tiene el derecho de postular para sí una vida inacabable. ¿No permitirá la reflexión sobre ese dato atisbar alguna respuesta a la cuestión que, según el propio filósofo, resume todos los esfuerzos de la filosofía, a saber, la cuestión por el ser mismo del hombre?

\section{Abreviaturas utilizadas para citar las obras de Kant}

Ak Kant's gesammelte Schriften, hrsg. von der Deutschen Akademie der Wissenschaften zu Berlin, Berlin, I9O2 ss. (Los números romanos indican el tomo y los arábigos, las páginas).

EaD Das Ende aller Dinge

FM Welches sind die wirklichen Fortschritte, die die Metaphysik seit Leibnitzens und Wolf's Zeiten in Deutschland gemacht hat?

$K p V$ Kritik der praktischen Vernunft

$K r V$ Kritik der reinen Vernunft (citada, como es usual, según la paginación de la primera $[\mathrm{A}]$ y segunda $[\mathrm{B}]$ ediciones)

KU Kritik der Urteilskraft 
MpVT Über das Misslingen aller philosophischen Versuche in der Theodicee

Prol Prolegomena zu einer jeden künftigen Metaphysik

Refl Reflexionen zur Metaphysik

RezHerder Recensionen von J.G. Herders Ideen zur Philosophie der Geschichte der Menschheit

TG Träume eines Geistersehers, erläutert durch Träume der Metaphysik

VNAEF Verkündigung des nahen Abschlusses eines Traktats zum ewigen Frieden in der Philosophie. 